\title{
A REVIEW OF ORDER PICKING IMPROVEMENT METHODS
}

\author{
Johan Oscar Ong ${ }^{*}$, Don Thomas Joseph \\ Industrial Engineering Department, Faculty of Engineering \\ President University
}

\begin{abstract}
As a crucial and one of the most important parts of warehousing, order picking often raises discussion between warehousing professionals, resulting in various studies aiming to analyze how order picking activity can be improved from various perspective. This paper reviews various past researches on order picking improvement, and the various methods those studies analyzed or developed. This literature review is based on twenty research articles on order picking improvement viewed from four different perspectives: Automation (specifically, stock-to-picker system), storage assignment policy, order batching, and order picking sequencing. By reviewing these studies, we try to identify the most prevalent order picking improvement approach to order picking improvement.
\end{abstract}

Keywords: warehousing; stock-to-picker; storage assignment; order batching; order picking sequencing; improvement

\section{Introduction}

As an essential part warehouse and inventory management operations, warehousing professionals have long identified order picking as the highest priority activity in the warehouse for productivity improvement. There are several reasons for their concern. The first reason is that order picking is the most costly activity in a warehouse. Around 55\% percent of all operating costs in a typical warehouse can be attributed to order picking (Tompkins et al., 1996). The second reason is that order picking activity has become increasingly difficult to manage due to the introduction of operating programs such as Just-In-Time (JIT) principle, cycle time reduction, quick response, and new marketing strategies such as micromarketing and megabrand strategies. These programs require smaller orders to be delivered to customers in greater frequency and more stock keeping units, or SKUs, to be incorporated in the order picking system. As a result, the requirements to maintain throughput and accuracy have increased significantly. The third reason is the increased emphasis on quality improvements and customer service, forcing warehouse managers to focus more on minimizing product damage and transaction time and improve picking accuracy. The last reason is the limited availability of labor and high hurdle rates (due to uncertain business conditions and environment) have hindered the warehouse management to utilize more manpower and invest on more advanced equipment to keep up with the increased requirements.

\footnotetext{
${ }^{*}$ Penulis Korespondensi.

email: johanoscarong@gmail.com
}

There are a few ways to improve order picking productivity in without increasing staffing or making significant investments for highly automated equipments, ranging from those that takes very little effort to implement like eliminating paperwork and other unnecessary elements in picking, to those that requires some investment or adherence a certain approach such as installing a stock-to-picker system or sequencing pick order to reduce travel time. This paper will address approaches that fall into the latter category, including but not exclusive to those mentioned earlier, and how they fare in improving order picking procedure.

\section{Various Approaches}

Researchers have used of various methods and approaches in the attempt to improve order picking activity. Most of the rigorously analyzed methods are those that require significant computational effort or calculation, i.e. in the 'more difficult' end of complexity/difficulty level. However, these methods typically produce more significant improvements to the whole activity. Those methods are utilization of stock-to-picker system, order batching, storage assignment policy, and order picking sequencing

\section{Stock-to-Picker System}

Typically, there are 3 types of order fulfillment/picking strategy: picker-to-stock, stockto-picker, and automated dispensing system (Pazour and Meller, 2012). In picker-to-stock, items are situated in fixed locations and pickers would have to travel to those locations to conduct extractions. Stock-to-picker strategy utilizes material transportation technologies to bring items toward the pickers situated in stationary pick locations. Such 
technologies include, but not limited to, carousel (vertical or horizontal), vertical lift module (VLM), and mini-load automated storage and retrieval system (AS/RS). Automated dispensing system eliminates all needs of manual operations and physical picking activity. As the explanation implies, the requirements for initial investments and maintenance expenses are high with the increasing automation in the activity. The more advanced level of sophistication also makes complete automation difficult to implement. With less investment compared to fully automated picking and generally better productivity and accuracy compared to picker-to-stock strategy, stockto-picker strategy can be a more reasonable option in improving order picking activity.

Most of the journals on warehouse automation or application of material transportation and AS/RS found focus not on how introducing the system would improve the operations throughput/productivity but in calculating the operational throughput and analyzing the potential of such sophistication. Bosier et al. (2012) produced an analysis of utilizing various strategies for two types of two-carousel system, unidirectional carousels and bidirectional carousels. Meller and Klote (2004) developed an analytical model to determine the throughput of pods of carousels and Vertical Lift Modules with human order-pickers.

\section{Storage Assignment Policies}

Rouwenhorst et al. (2000) identified several types of storage assignment policy: random storage, closest open location storage, dedicated storage, class-based storage, and family grouping. Random storage is an assignment policy where items coming into a warehouse are located in any of the empty locations available arbitrarily, without certain consideration. Warehouse using this policy generally has good space utilization, but random assignment makes product identification more difficult and the resulting travel more time consuming. The closest open location storage dictates that incoming items are assigned to the nearest available location from receiving area. This means that storage locations near the receiving area will have greater utilization compared to the further ones. Dedicated storage policy is concerned with assigning fixed locations to certain products. The purpose is so that workers become more familiar with product position. Space utilization in a warehouse using this policy is typically low. Class-based storage policy utilizes a classification method cluster items into fast, intermediate, and slow moving items. In $\mathrm{ABC}$ analysis, this translates to $\mathrm{A}, \mathrm{B}$, and $\mathrm{C}$-items, respectively. Family grouping policy concerns with possible items relationship, such frequent pairing/grouping of items within an order.

Chackelson et al. (2011) compared class-based storage and family grouping policy to see which assignment policy fares better using a AnyLogic simulation software. Their warehouse model consists of 6 aisles, 144 uniform locations per aisle, with return routing policy. Items are clustered into 3 classes; A, B, and C. Picker travel rate is set at 80 meters per minute and the pallet capacity is 1400 $\mathrm{dm}^{\wedge} 3$. The resulting simulation shows that classbased storage, combined with batching policy, has great impact on reducing travel distance. Fontana and Cavalcante (2011) combined ELECTRE TRI method and $\mathrm{ABC}$ analysis to categorize items for class-based storing purposes. The criteria for product classification are demand, product size, profitability, and sensitivity (how the customer would react to different level of service). Each product criterion are scaled between 0 and 100, and classification of said products are divided into two: optimistic (using the highest-scoring criterion as consideration) and pessimistic (using the lowest-scoring criterion as consideration). In their research on improving product location assigning and order picking, Renaud and Ruiz (2007) utilized the closest open storage policy with several location sorting method. The results suggested $11.25 \%$ improvement in productivity. Tsige (2013) compared 3 principle policies in storage assignment: random, class based, and family grouping. Other than the usual $\mathrm{ABC}$ analysis, Tsige (2013) also used Cube-per-order index (COI) to rank items based on their popularity. Furthermore, interaction frequency heuristics order oriented slotting (IFH-OOS) is used to further refine storage assignment after using COI. The idea of IFHOOS is to pair items with high interaction next to each other. In a uniform setting where orders are generated from normal distribution, random storage policy came out as the best policy. If the orders distribution adheres to Pareto law (20\% of items make up $80 \%$ of transactions), IFH-OOS outperforms the other three assignment methods.

\section{Order Batching}

Order batching is a way to improve picking productivity. The idea is by grouping orders to be simultaneously picked in a single tour, the theoretical time per pick can be reduced. The aim in batch picking is to determine an optimum order batching to minimize travel distance or time.

Henn and Wascher (2010) proposed two approaches to order batching based on the tabu search principle: the tabu search algorithm (TS) and Attribute-Based Hill Climber (ABHC). These approaches are then tested on two routing heuristics, S-shape and largest gap. Henn (2009) modified offline/static order batching heuristic approaches, such as first-come-first-served (FCFS), savings algorithm $\mathrm{C} \& \mathrm{~W}$ and iterated local search (ILS), to be used for on-line order batching cases. Four selection rules are suggested for this model: FIRST, which chooses the first batch; SHORT, which determines a batch with shortest order time; LONG, which determines a batch with the longest order time; SAV, which calculates 
each batch's savings value. Simulations are done using S-shaped and largest gap routing strategies. The result suggested that ILS produces the best results among the three, while the LONG and SAV selection rules provided the best completion times regardless of batching heuristics. Hong et al. (2011) solved large scale order batching problem in parallel pick aisle using heuristic route-packing based order batching procedure (RBP). The result suggested that in a narrow-aisle order picking system (10 aisles) with large number of orders (2180), RBP generates a near optimal solution. Hong et al. (2012) proposed an integrated batching and sequencing method called indexed batching model (IBM), for narrow-aisle batch picking problem with consideration to picker blocking (congestion problem). This method aims to reduce total retrieval time, which is the sum of travel time, picking time, and congestion/blocking delays. Result showed 5-15\% reduction in total retrieval time, with a major part of that reduction is from minimizing picker blocking. Hsu et al. (2004) proposed a genetic algorithm-based order batching method (GABM). The proposed approach, according to the paper, does not require the computation of order/batch proximity and the estimation of travel distance, as it directly minimizes the total travel distance.

\section{Order Picking Sequencing}

Order picking sequencing program focuses not only on determining the order of items extraction, but also on the route/path taken in travelling to pick locations. This idea applies not only to warehouses with manual picking operations but also to those that utilize stock-to-picker system and even fullyautomated picking system.

Ratliff and Rosenthal (1982) came up with an order-picking algorithm for a rectangular warehouse without a cross aisle in the middle. The model is capable of finding minimum picking route with the previously explained configuration. Mohanasundaram et al. (n.d.,) addressed the order picking sequence problem in a single aisle automated warehouse using genetic algorithm approach. Roodbergen and De Koster (2001) came up with a combined order picking heuristic using dynamic programming method and the improvement of it named combined+ heuristics. Those heuristics, along with other various order picking heuristics such as Sshape, largest gap, and aisle by aisle, are compared by simulating them on different warehouse configurations and order sizes. 2000 replications of each order are done to find the average travel time for all heuristics. Theys et al. (2009) reported average savings in route distance of up to $47 \%$ when using Lin-Kernighan-Helsgaun (LKH) heuristics to determine order picker routing in a warehouse. Kim et al. (2003) utilized x-based coordinate heuristic and clustering based algorithm to solve order picking sequence problem in an actual automated industrial warehouse. The warehouse consists of 16 pick zones and can hold up to 400,000 items at any time, with 100,000 items typically picked daily. De Koster and Van Der Poort (1998) compared the polynomial algorithm of Ratliff and Rosenthal (1982) with Sshaped heuristic that is seen as a commonly used approach in practical picking situations. These two methods are compared in three realistic order picking situations; narrow-aisle high-bay pallet warehouse, picking in shelf are with decentralized depositing of picked items, and conventional order picking from wide-pallet locations. The result showed $7 \%$ to $34 \%$ reduction in travel time per route with the polynomial algorithm. Shouman et al. (n.d.) introduced two routing heuristics; block-aisle1 and block-aisle2, and compare them with previously proposed heuristics including combined heuristics developed by Roodbergen and De Koster (2001). The heuristics were simulated on 80 different situations, and blockaisle2 algorithm performed best in $55 \%$ of the situations. Chan and Cheng (2012) developed a hybrid algorithm that addresses both joint order batching and order picking. The hybrid algorithm consists of two phases. First, joint order batching problem is addressed using particle swarm optimization (PSO) algorithm), then ant colony optimization (ACO) algorithm is utilized to find the most efficient traveling route to pick the batched orders. Ascheuer et al. (1998) compares several online asymmetric traveling salesman problem (ATSP) heuristics to solve order picking problem in an automated warehouse. The compared strategies are priority rule, random, optimal solution, greedy heuristic, greedy+2opt heuristic, greedy+3opt heuristic, fit-in, farthest insertion heuristic, list insertion heuristic, random insertion heuristic, best insertion heuristic, and shuffle heuristic. The optimization of the ATSP problem resulted in $40 \%$ reduced unloaded travel time.

\section{Conclusion}

From the 20 journals studied in this paper, journals on order picking are featured the most. 9 out of $20(45 \%)$ journals studied on this paper are on order picking sequencing and routing heuristics. The idea of combining 2 approaches in improving order picking operations is also a possibility, as Chan and Cheng (2012) proposed in their paper using a twophased method.

\section{References}

Ascheuer, N., Grotschel, M., Abdel-Hamid, Atef A., 1998, "Order Picking in an Automated Warehouse: Solving Online Asymmetric TSPs", Konrad-Zuse-Zentrum

fur Informationstechnik Berlin.

Bosier, R., Vlasiou, M., Adan, I., 2012, "Analytical Properties of Two-Carousel Systems", Eindhoven University of Technology. 
Chackelson, C., Errasti, A., Cipres, D., Alvarez, M.J., 2011, "Improving Picking Productivity by Redesigning Storage Policy Aided by Simulations Tools", 5th International Conference on Industrial Engineering and Industrial Management.

Chan, L., Cheng, C., 2012, "Joint Order Batching and Picker Routing Using Two-Phased Algorithm", Proceedings of the Asia Pacific Industrial Engineering \& Management Systems Conference 2012.

De Koster, R, Van Der Poort, E., 1998, "Routing Orderpickers in a warehouse: a Comparison between Optimal and Heuristic Solutions", IIE Transactions (1998) 30, 469-480.

Fontana, Marcele E., Cavalcante, Cristiano Alexandre V., 2011, “ABC Categorization Using the ELECTRE TRI Method to Storage Location Assignment", XLIII Simposio Brasileiro de PESQUISA OPERACIONAL.

Henn, S., 2009, "Algorithms for On-line Order Batching in an Order Picking Warehouse", FEMM Working Paper No. 34, October 2009.

Henn, S., Wascher, G., 2010, "Tabu Search Heuristics for the Order Batching Problem in Manual Order Picking Systems", FEMM Working Paper no.7, February 2010.

Hong, S., Johnson, Andrew L., Peters, Brett A., 2012, "Batch-Picking in Narrow-Aisle Order Picking Systems with Consideration for Picker Blocking", European Journal of Operational Research $x x x$ (2012) $x x x-x x x$.

Hong, S., Johnson, Andrew L., Peters, Brett A., 2011, "Large-Scale Order Batching in Parallel-Aisle Picking Systems", Department of Industrial and Systems Engineering, Texas $A \& M$ University.

Hsu, C., Chen, K., Chen, M., 2004, "Batching Orders in Warehouses by Minimizing Travel Distance with Genetic Algorithm", Computers in Industry 56 (2005) 169-178

Kim, B., Heragu, Sunderesh S., Graves, Robert J., Onge, Art St., 2003, "Clustering-Based OrderPicking Sequence Algorithm for an Automated Warehouse", Int. J. Prod. res., 2003, vol. 41, no. 15, 3445-3460.
Meller, Russell D., Klote, John F., (2004), "A Throughput Model for Carousel/VLM Pods", IIE Transactions (2004)36, 725-741.

Mohanasundaram, K.M., Ravichandran, A.T., Balamurugan, K., Anitha, G., n.d., "A Genetic Algorithm Approach to Optimize the Order Picking Time in a Single Aisle Warehouse", web.tuke.sk/fvtpo/journal/pdf08/2-str-8387.pdf.

Pazour, Jennifer A. and Meller, Russell D., 2012, "Modeling the Inventory Requirement and Throughput Performance of Picking Machine Order-Fulfillment Technology", Progress in Material Handling Research: 2012, Material Handling Institute, Charlotte, NC.

Ratliff, H. D. and Rosenthal, A. S., 1983, Order-

Picking in a Rectangular Warehouse: a

Solvable Case of the Traveling Salesman Sroblem. Operations Research, 31, 507- 521.

Renaud, J., Ruiz, A., 2007, "Improving Product Location and Order Picking Activities in a Distribution Center", Interuniversity Research Centre on Enterprise Networks, Logistics and Transportation (CIRRELT).

Roodbergen, Kees J., De Koster, R., 2001, "Routing Methods for Warehouses with Multiple Cross Aisles", International Journal of Production Research, 39:9, 1865-1883.

Rouwenhorst B, Reuter B, Stockrahm V et al, 2000, Warehouse Design and Control: Framework and Literature Review, European Journal of Operational Research 122: 515-533

Shouman, M.A., Khater, M., Boushaala, A., n.d., "Comparisons of Order Picking Methods for Warehouses with Multiple Cross Aisles", Zagazig University

Theys, C., Braysy, O., Dullaert, W., Raa, B., 2009, "Using a TSP Heuristic for Routing Order Pickers in a Warehouse", European Journal of Operational Research 200 (2010) 755-763

Tompkins et al., (1996), Facilities Planning Second Edition, Canada: John Wiley and Sons, Inc.

Tsige, Mersha T., 2013, "Improving Order-Picking Efficiency via Storage Assignment Strategies", Master Thesis: Industrial Engineering and Management, University of Twente, Enschede, Netherlands. 